\title{
Modification of Carbon Steel by Laser Surface Melting: Part II: Effect of Laser Beam Power on Microstructural Features and Surface Hardness
}

\author{
Hashem F. El-Labban, M. Abdelaziz and Essam R.I. Mahmoud \\ Faculty of Engineering, King Khalid University, Abha, Kingdom of Saudi Arabia
}

Received 2013-12-03; Revised 2013-12-16; Accepted 2014-01-02

\begin{abstract}
The surface hardness has an important effect on the wear resistance of different materials. The present study aims to improve the surface hardness of carbon steel through the application of laser surface melting with suitable conditions. The laser beam power and travelling speed are the main factors that affect the properties of the treated zone. In this study, three different conditions of laser beam power $(1800,1500$ and $1200 \mathrm{~W})$ at fixed travelling speed of $1000 \mathrm{~mm} \mathrm{~min}^{-1}$ were chosen to study the effect of laser beam power. The resulted laser treated specimens were investigated in macro and microscopically scale using optical and scanning electron microscope. Hardness measurements were also carried out through the thickness of the laser treated zones. The laser treated areas with all used powers results in melted and solidified zone on the surface of the steel. The laser power of $1800 \mathrm{~W}$ results in the deepest value of the laser treated zone (about $1.7 \mathrm{~mm}$ ). Moreover, by increasing the laser power, the width of the treated zone was slightly increases. At areas near the free surface, large martensite plates were observed in higher laser power $(1800 \mathrm{~W})$, while longer acicular martensite was observed in lower laser power $(1200 \mathrm{~W})$. For laser power of $1800 \mathrm{~W}$, the bainite structures in ferrite grains were more pronounced in larger areas and in closer areas to the free surface. On the other hand, the lower laser power shows higher hardness on the free surface than that of higher power. The sizes of Heat Affect Zone (HAZ) areas were increased by increasing the laser beam power. In all conditions, the heat affected zone areas were composed of partially decomposed pearlite in ferrite grains.
\end{abstract}

Keywords:X 52 Steel, Laser Surface Treatments, Laser Surface Melting, Martensitic Structure, Nanostructure, Microhardness

\section{INTRODUCTION}

In different industrial sectors, there is an urgent need to improve the performance of material surface under wear and corrosion environments, which cannot be fulfilled by the conventional surface modifications and coatings. Arai (1992) reported that the Conventional Surface Engineering (CSE) techniques such as carbonizing, nitriding, Chemical Vapor Deposition (CVD), physical vapor deposition (PVD) and Thermo Reactive Deposition and diffusion (TRD) improve the wear resistance, only under appropriate conditions. Laser represents one of the most important inventions of 20th century. With their development, it is possible to get highly intensive, monochromatic, coherent and highly polarized light waves (Hoffmann and Dierken, 2003; Yasavola et al., 2013). One way to improve the surface properties of materials is the laser surface engineering. Laser surface engineering encompasses several applications that are mainly related to enhancing one of the surface dependent properties, like hardness, friction, fatigue and resistance to wear, corrosion

Corresponding Author: Essam R.I. Mahmoud, Faculty of Engineering, King Khalid University, Abha, Kingdom of Saudi Arabia Tel: +966543546868 
(Majumdar et al., 2010). The surface of metals can be modified by the application of one or more of suitable laser surface treatments (Costa et al., 2004; Kanapenas, 2001). The simplest application of laser processing, laser heating, involves the rapid heating of the surface layers to a temperature just below the melting point, followed by rapid cooling (Baker, 2010).

The Laser Surface Melting (LSM) (Benyounis et al., 2009), Laser Surface Alloying (LSA) (Sun et al., 2010) and Laser Surface Cladding (LSC) (Liu et al., 2007) are examples of the suitable treatments which can also be applied for surface modification. Some of the advantages of these surface treatments include flexibility and the possibility of treating small areas, leaving the others parts unaffected. In laser surface melting, no additional alloying elements are incorporated. Since the bulk of the material is unaffected by the laser, a large heat sink is provided for the subsequent rapid cooling of the melted surface. This can result in non equilibrium fine microstructures with superior homogeneity, which may confer substantial increases in hardness and wear resistance of the material surface in a very short time (Darmawan et al., 2007; D’Oliveira et al., 2001). Moreover, laser surface treatments have little thermal penetration, resulting in little distortion, process flexibility due to software control and possibilities of automation. As reported in (Bhadeshia, 2012), the surface performance of the specimens treated by LSM is modified mainly by the homogenization and refinement of the microstructure. In addition, different precipitates may be formed in some alloys and the supersaturation of some phases increased due to nonequilibrium solidification. However, the modification is limited, because the composition of the melted layer is the same with respect to the substrate. The modification can be improved by controlling of the treatment parameters. The power and travelling speed of laser beam are main process parameters. Therefore, the effect of these parameters were studied in the present and another articles. The present work aims to study the effect of laser beam power on microstructural features and hardness of surface and subsurface layers of X52 carbon steel.

\section{MATERIALS AND METHODS}

Grade X 52 steel of chemical composition listed in Table 1 was used as a base metal. The microstructure of the base metal consisted of annealed ferrite (white region) and full laminated pearlite (dark region) microstructure, as shown in the optical micrograph in Fig. 1. The mechanical properties of the base metal are tabulated in Table 2.
Table 1. Chemical analysis of base metal (wt \%)

\begin{tabular}{lllllll}
\hline $\mathrm{C}$ & $\mathrm{Si}$ & $\mathrm{Mn}$ & $\mathrm{P}$ & $\mathrm{S}$ & $\mathrm{Cr}$ & $\mathrm{Fe}$ \\
\hline 0.22 & 0.21 & 1.22 & 0.05 & 0.01 & 0.05 & $\mathrm{Bal}$ \\
\hline
\end{tabular}

Table 2. Mechanical properties of the base metal.

\begin{tabular}{llll}
\hline $\begin{array}{l}\text { Yield strength, } \\
\mathrm{MPa}\end{array}$ & $\begin{array}{l}\text { Ultimate tensile } \\
\text { strength, } \mathrm{MPa}\end{array}$ & $\begin{array}{l}\text { Elongation, } \\
\%\end{array}$ & $\begin{array}{l}\text { Hardness, } \\
\text { Hv0.1 }\end{array}$ \\
\hline 307 & 417 & 32 & 176 \\
\hline
\end{tabular}

The laser machine operated at powers of 1200, 1500 and $1800 \mathrm{~W}$, at a fixed travelling speed of $1000 \mathrm{~mm}$ $\min ^{-1}$. The focusing distance was $10 \mathrm{~mm}$. The pressure and flow rate of $\mathrm{N}_{2}$ gas: 0.5 bar and $27 \mathrm{~L} \mathrm{~min}^{-1}$, respectively. The microstructures of the treated zone and base metal were investigated using optical and scanning electron microscopes. The microhardness of treated zone and subsurface layers at different conditions was evaluated using a microhardness tester.

\section{RESULTS}

\subsection{Effect of Treatment Conditions on the Microstructure}

Macro and microscopic appearances of the treated (melted and solidified layer) and Heat Affected Zone (HAZ) produced by application of the laser surface melting of different laser powers are shown in Fig. 2-8. In general, the depth of the treated zone was decreased by decreasing the laser power, as clearly shown in Fig. 2. At laser power of $1800 \mathrm{~W}$, the heat input became very large and in consequence, the cooling rate became relatively slow. As a result of this main address, the depth of the laser treated zone reached $1.7 \mathrm{~mm}$. When the laser power decreased to $1500 \mathrm{~W}$, The generated heat input reduces the cooling rate and in subsequence affect on the depth of the treated zone which reduced to about $1.3 \mathrm{~mm}$. By reducing the laser power to be 1200 $\mathrm{W}$, the resulted treated zone depth was slightly decreased to about $1.2 \mathrm{~mm}$.

The microstructures of the treated zone after laser power of $1800 \mathrm{~W}$, are shown in Fig. 3 and 4. The cooling rate after this huge amount of heat input is not fast enough to form full martensite structure even at or near the treated zone free surface. The results show that the martensite appeared inside a ferrite grains even near the free surface. At areas little bit far from the free surface, mixed acicular martensite and lower bainite are appeared in large ferrite grains. Moreover, the results show large heat affected zone due to this lower cooling speed. 

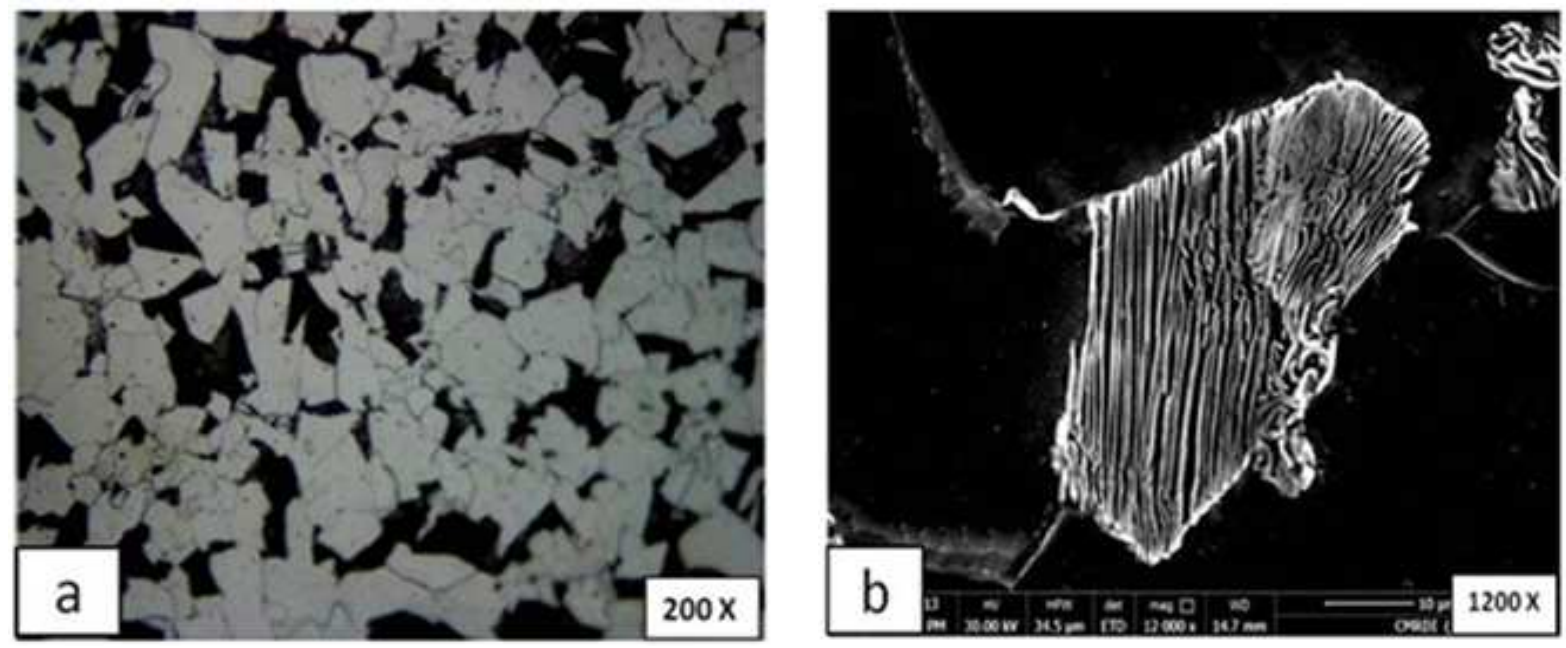

Fig. 1. Microstructure of the untreated steel (a) Optical micrograph showing normal ferrite (white color)-pearlite (dark color) structure and (b) SEM image showing full laminated pearlite structure with larger magnification
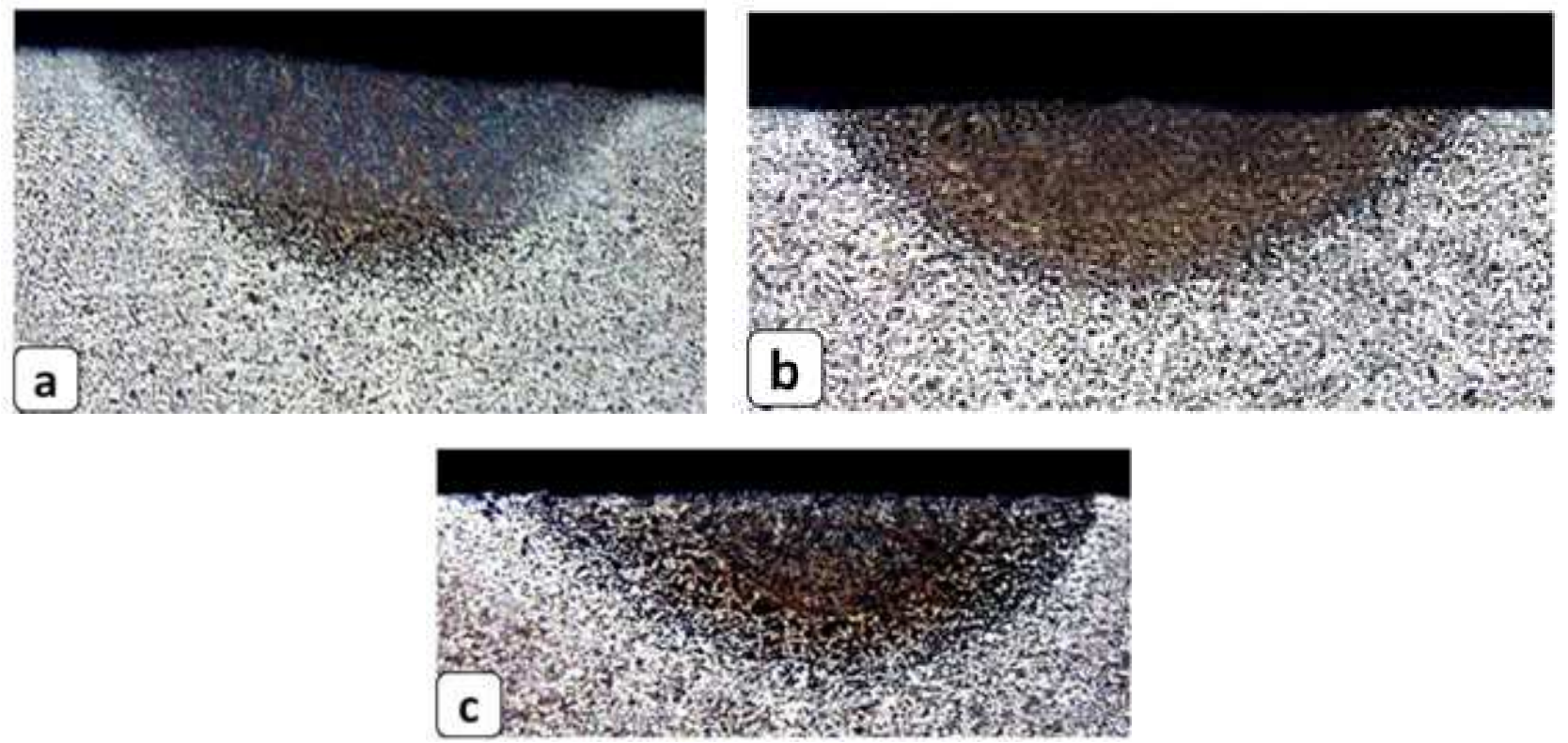

Fig. 2. Optical macrographs for treated zones produced by laser power of (a) 1800 , (b) 1500 and (c) $1200 \mathrm{~W}$

The treated (melted and solidified layer) and Heat Affected Zone (HAZ) produced by application of the laser surface melting at $1500 \mathrm{~W}$ and $1000 \mathrm{~mm} \mathrm{~min}^{-1}$ are shown in Fig. 5 and 6. The heat input that generated by laser power of $1500 \mathrm{~W}$ reduces the cooling rate and in subsequence affect macro and microscopically of the resulted treated zone. Large batches or plates of martensite appeared again in areas very near to the free surface. This is due to the fast heat dissipation by radiation to the surrounding fresh air. In the center of the treated zone, batches of mixed martensite and bainite inside fine grained ferrite structure are clearly recognized. In this zone, the resulted cooling rate is suitable for production of this mixed microstructure. The power density in this case is lower than that in case of power $1800 \mathrm{~W}$. Accordingly, the batches of martensite and bainite mixed structure are larger and the ferrite grains are finer. 

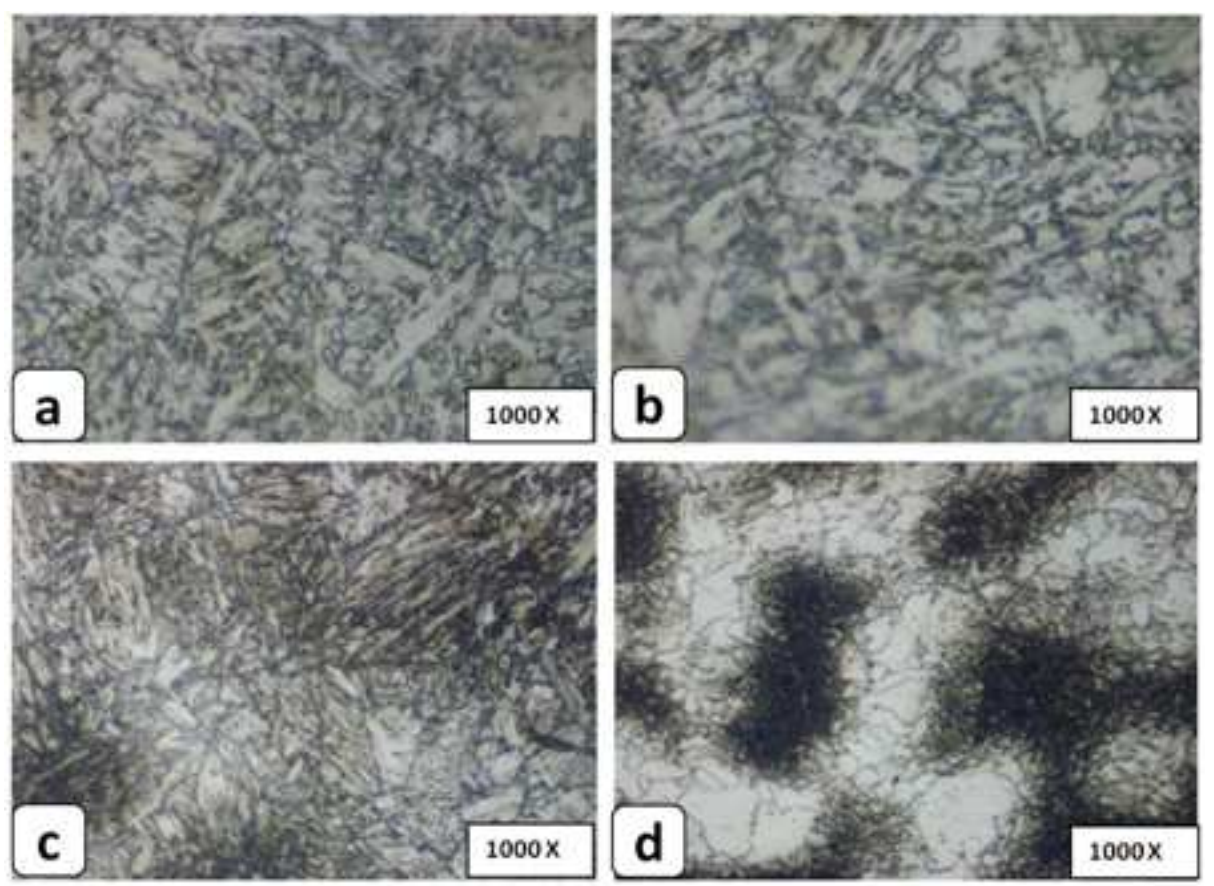

Fig. 3. Optical micrographs for microstructures produced by laser Power of $1800 \mathrm{~W}$, where (a) near the free surface of the treated zone, (b) at the center of the melted and solidified zone, (c) at the end of the melted and solidified zone, and (d) at the Heat Affected Zone (HAZ) of the treated zone
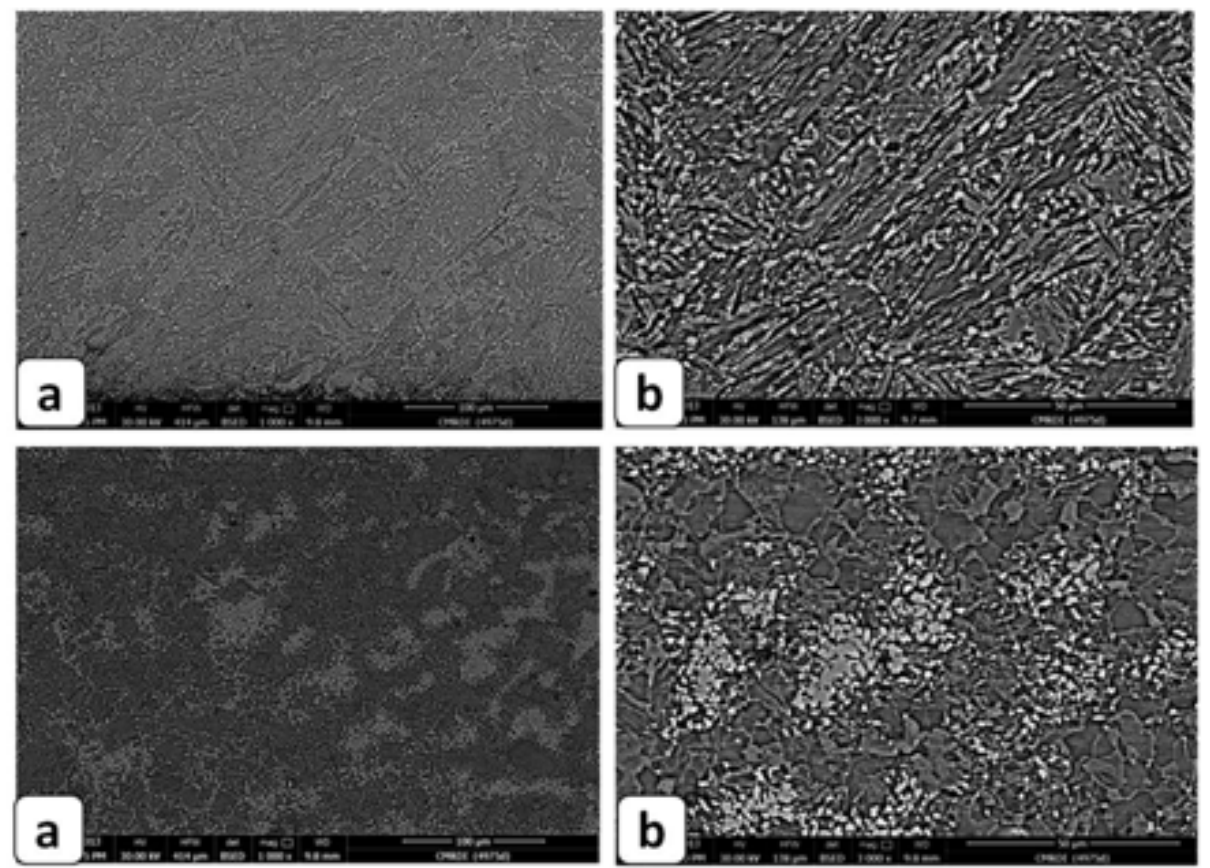

Fig. 4. SEM images of microstructure produced by laser Power of $1800 \mathrm{~W}$, where (a) and (b) near the free surface of the treated zone and (c) and (d) at the lower part of the treated zone 

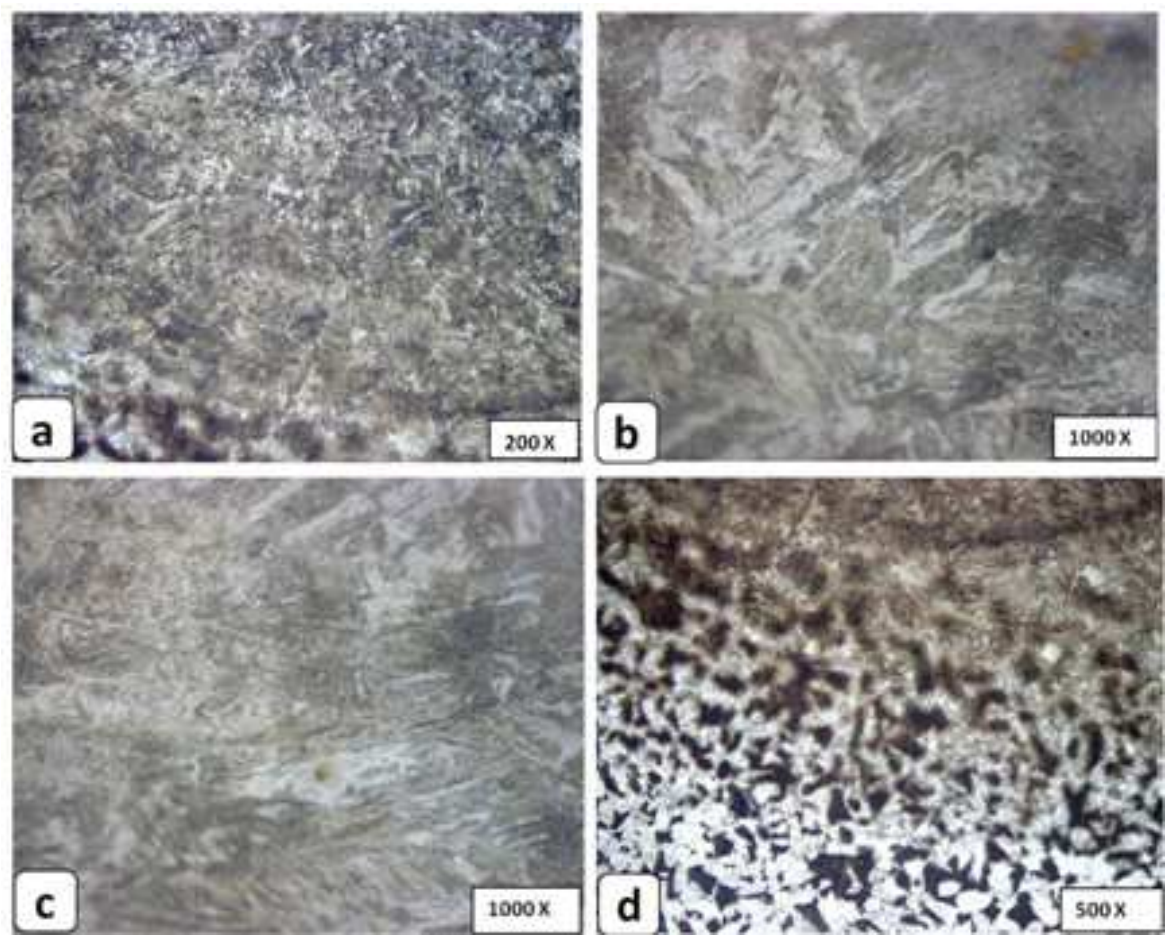

Fig. 5. Optical micrographs for microstructures produced by laser Power of $1500 \mathrm{~W}$ where, (a) Low magnified micrograph of the melted and solidified zone, (b) and (c) High magnified micrographs of the melted and solidified zone and (d) Low magnified micrograph at the interface between the laser treated and untreated zones
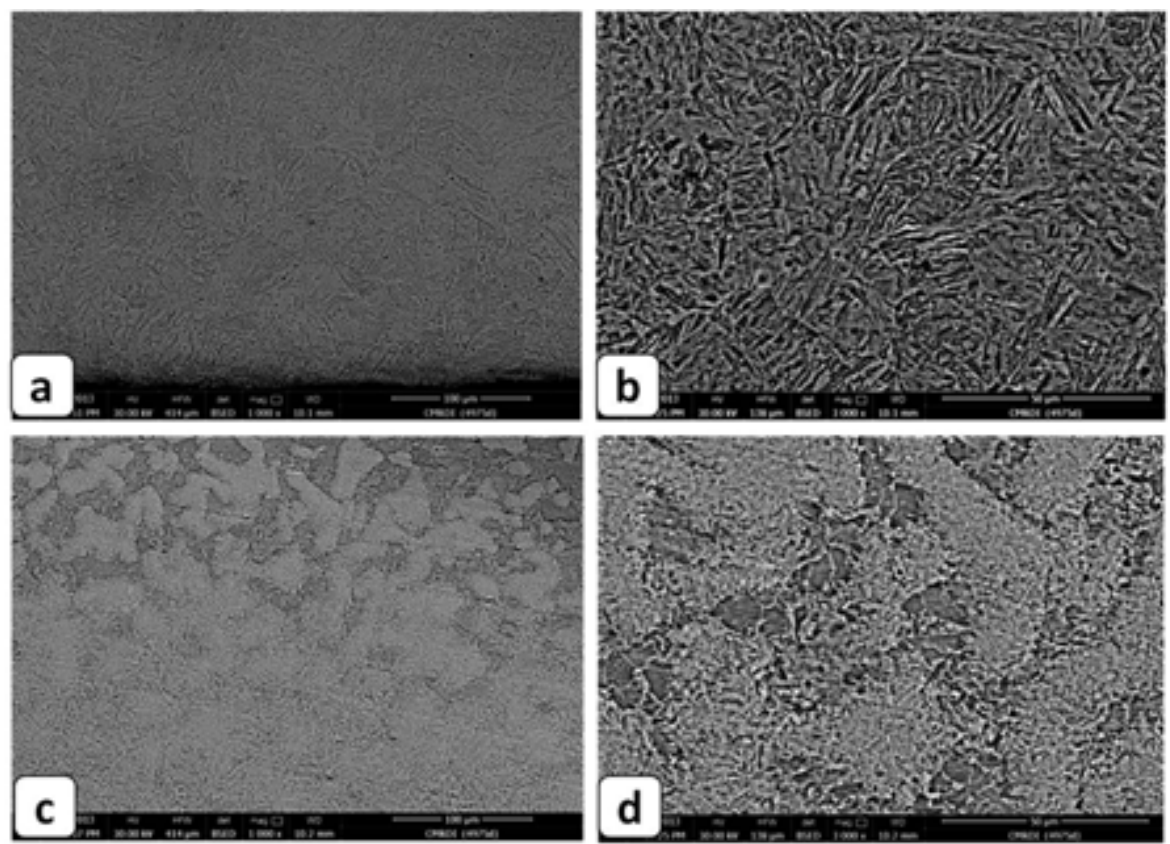

Fig. 6. SEM images for microstructure produced by laser Power of $1500 \mathrm{~W}$ where, (a) and (b) at areas very near to the free surface and (c) and (d) at the end of the treated zone 
Hashem F. El-Labban et al. / American Journal of Engineering and Applied Science 6 (4): 384-392, 2013
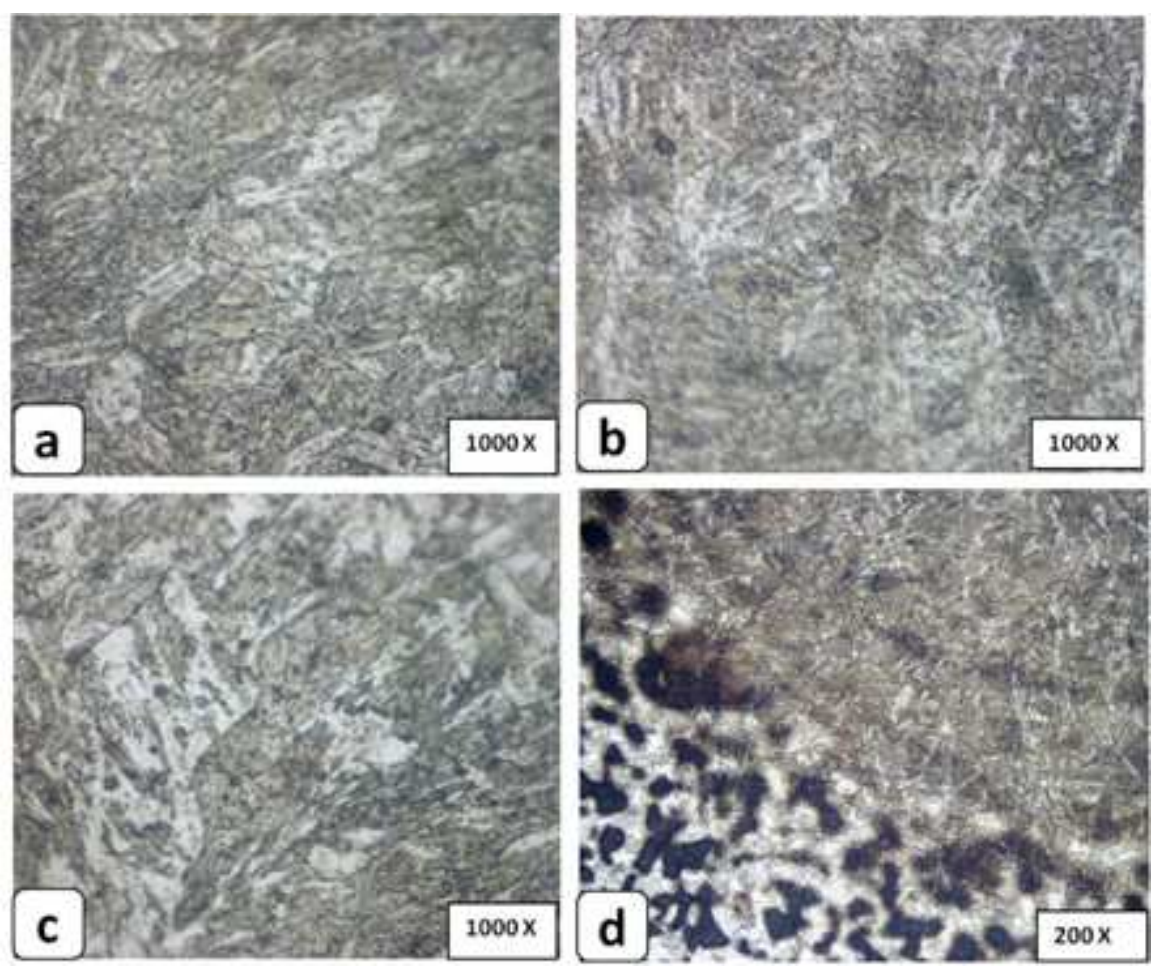

Fig. 7. Optical micrographs for microstructures produced by laser power of $1200 \mathrm{~W}$ where, (a) at areas very neat to the free surface, (b) at the center of the melted and solidified zone, (c) at areas near the lower part of the treated zone and (d) at the interface between the laser treated and untreated zones
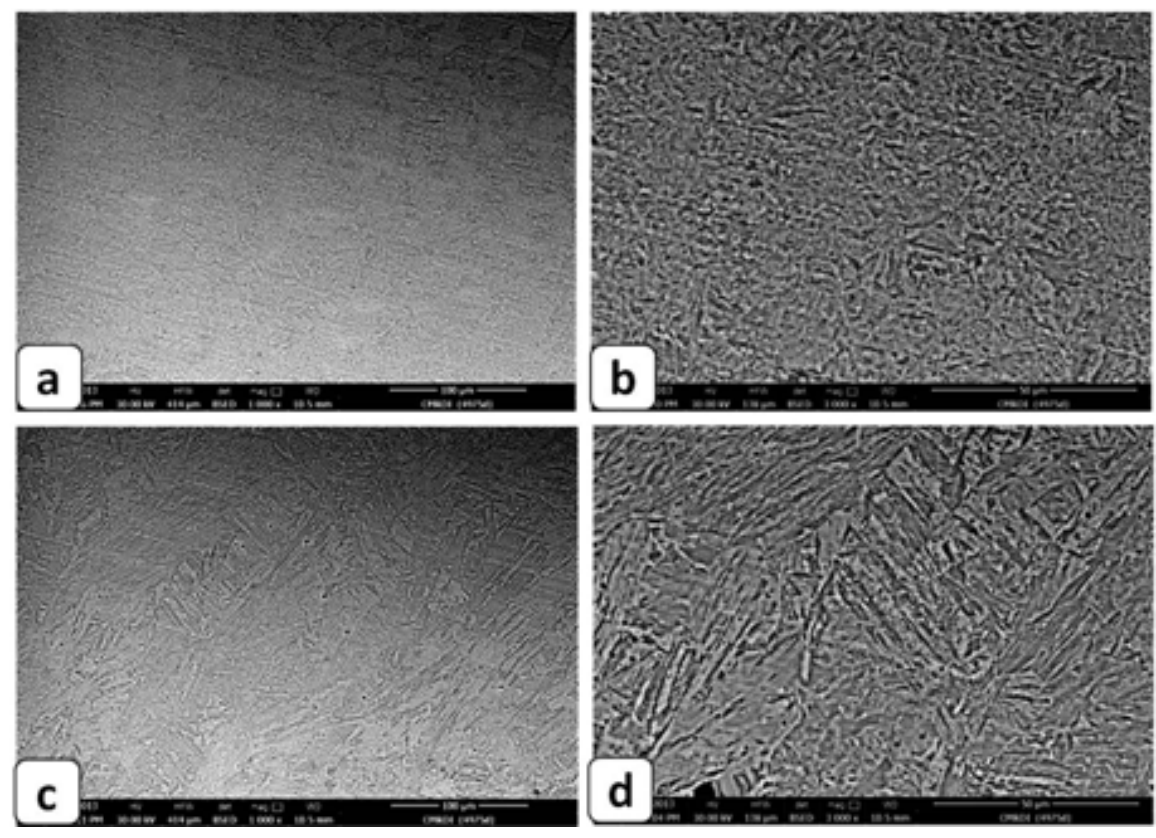

Fig. 8. SEM images for microstructure produced by laser power of $1200 \mathrm{~W}$ where, (a) and (b) at areas very near to the free surface and (c) and (d) at the center of treated zone 


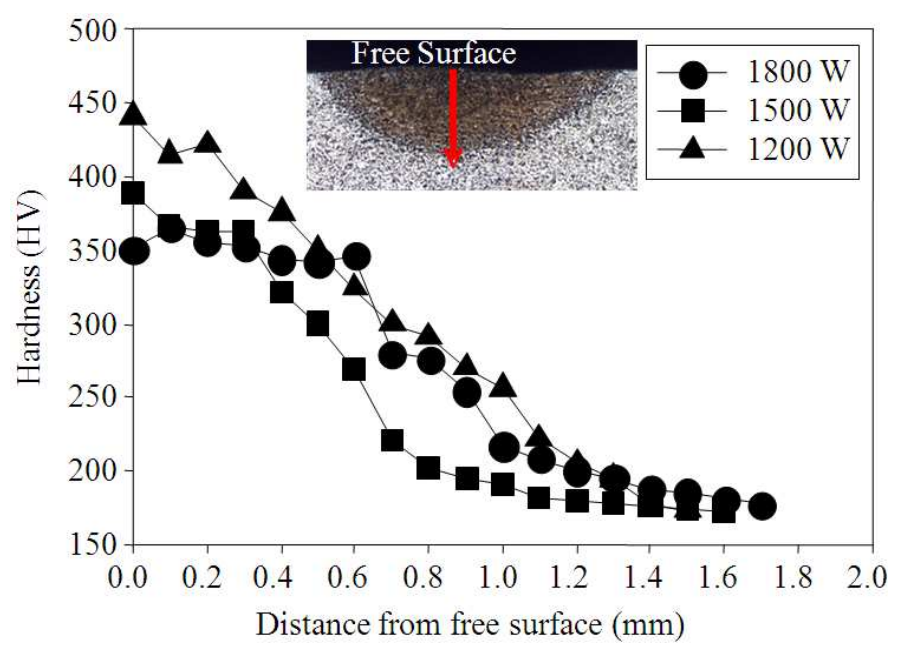

Fig. 9. Hardness distributions through the depth of laser treated zone at different laser powers at fixed travelling speed of $1000 \mathrm{~mm} \mathrm{~min}^{-1}$

By reducing the laser power to be $1200 \mathrm{~W}$, the resulted treated zone shows some changes, as shown in details in Fig. 7 and 8. Firstly, the treated zone depth was slightly decreased to about $1.2 \mathrm{~mm}$. when the laser power is decreased, the heat input will be also decreased. As a subsequence, the depth of the metal that is affected will be decreased. Regarding the width of the treated zone, it records about $3 \mathrm{~mm}$.

Microscopically, small plate of fine acicular martensite is appeared near the free surface. Going inside the laser treated zone, larger plates of the martensite are recognized. Near the end of the treated zone, large martensite plates are found inside ferrite grains.

\subsection{Effect of Laser Treatment on Surface Hardness}

The hardness data is obtained through the micro hardness tester. The average value of hardness for the untreated base material is $176.4 \mathrm{HV}_{0.1}$. The hardness distributions through the depth of the laser treated zone at different powers are shown in Fig. 9. The results indicated that laser power has a significant effect on the hardness of the surface and subsurface layers. The hardness of the free surface of near from it shows higher values at lower laser power. For example, at power of $1800 \mathrm{~W}$, the hardness reaches to only $350 \mathrm{HV}$, while of that of $1200 \mathrm{~W}$ can reach to $440 \mathrm{HV}$. On the other hand, the laser power has a straight effect on the depth of the hardness. As the laser power increases, the depth of the higher hardness went to a deeper depth inside the materials (Compare the plot of hardness of $1800 \mathrm{~W}$ and that of $1500 \mathrm{~W})$. The enhancement in hardness can mainly be attributed to the formation of fine martensitic structure. It was observed that the finer microstructure shows higher hardness values, especially at lower laser powers. This is due to rapid solidification processes in the surface melted and solidified zone. In the sub melted zone, lower hardness values were observed. This is due to the lower cooling rate which produces batches of mixed martensite and bainite inside fine grained ferrite structure. In all cases, the hardness values for the treated and heat affected zones are higher than those for the base metal. Moderate hardness in the transition zone was obtained due to the ferrite-partially decomposed pearlite structure produced in the HAZ.

\section{DISCUSSION}

The power of the laser beam is one of the main factors in laser surface melting which alter the depth and width of melted and heat affected zones to obtain desired surface properties. The above results indicated that this process parameter has a significant effect on the microstructural features and hardness of surface and subsurface layers. The heat input has a direct relationship with the laser power. When the laser power is increased, the heat generated is increased and in consequence, the depth of melted zone is increased. On the other hand, the higher power deceases to some limit the cooling rate after solidification. As consequence, the relatively slow cooling rate (that of higher power) decreases the amount of formed martensite and give the bainite structure and 
ferrite grains to be appeared in large areas as clearly shown in the previous micrographs. The rapid cooling after laser surface melting of lower laser powers (up to $10^{6 \circ} \mathrm{K} / \mathrm{s}$ ) leads to formation of fine martensite structure at the surface which improve the surface hardness (Luangpaiboon, 2011).

Moreover, the rapid cooling can also refine the microstructure, which improve not only the wear resistance, but also the corrosion and fatigue resistance. On the other hand, the depth of this higher hardness is limited by the lower power.

Solid state transformations occurring in the heat affected zone are due to carbon diffusion phenomena. As an assumption, cementite and ferrite plates which formed pearlite of the base metal are distant from, pearlite dissolution requires a diffusion of carbon atoms along a certain distance and a suitable time is required. In the present investigation, the treatment conditions applied are not suitable for complete decomposition of the pearlite. As a result, partial decomposition of pearlite is resulted. Therefore, there is an increase in hardness in this zone but with value lower than that in the melted and solidified zone. Generally and as shown in Fig. 9, in the sub melted zone, due to lower cooling rate, batches of mixed martensite and bainite inside fine grained ferrite structure of hardness lower than that of full martensitic structure formed in the melted zone but higher than that of the HAZ. In all cases, the hardness values for the treated and heat affected zones are higher than those for the base metal. Moderate hardness in the transition zone was obtained due to the ferrite-partially decomposed pearlite structure produced in the HAZ.

\section{CONCLUSION}

The surface of grade X52 steel was laser treated with different powers (1800, 1500 and $1200 \mathrm{~W})$ at fixed travelling speed of $1000 \mathrm{~mm} \mathrm{~min}^{-1}$. The resulted laser treated specimens were investigated in macro and microscopically scale using optical and scanning electron microscope. Hardness measurements were also carried out through the thickness of the laser treated specimens. The results obtained can be summarized as follows:

- The laser treated areas with all used powers results in melted and solidified zone on the surface of the steel

- Plates of acicular martensite structure were observed within the upper part of the melted and solidified zone in almost all experimental conditions, while some bainite structure in ferrite grains are detected in its lower part

- The laser power of $1800 \mathrm{~W}$ results in the deepest value of the laser treated zone (about $1.7 \mathrm{~mm}$ ). By increasing the laser power, the width of the treated zone was slightly increases

- Near the free surface, large martensite plates were observed in higher laser power $(1800 \mathrm{~W})$, while longer acicular martensite was observed in lower laser power $(1200 \mathrm{~W})$

- For laser power of $1800 \mathrm{~W}$, the bainite structures in ferrite grains were more pronounced in larger areas and in closer areas to the free surface

- The lower laser power show higher hardness on the free surface than that of higher power

- The Heat Affect Zone (HAZ) areas were increased by increasing the laser power. In all conditions, the heat affected zone areas were composed of partially decomposed pearlite in ferrite grains

- The microstructure of the base metal far from the laser treated areas show normal ferrite-sound pearlite microstructure

\section{ACKNOWLEDGEMENT}

This study is supported by the King Abdel-Aziz City of Science and Technology (KACST) through the Science and Technology Center at King Khalid University (KKU), Project No. (10-ENE1161-07). The authors thank both KACST and KKU for their financial support. Special Thanks to Prof. Ahmed Tahir, Vice President of KKU, Prof. Abd Alla AlSehemi, Head of the Scientific Research at KKU and Prof. Hoseen Al-Wadai, Dean of the Faculty of Engineering at $\mathrm{KKU}$, for their support.

\section{REFERENCES}

Arai, T., 1992. Tool materials and surface treatments. J. Mater. Process. Technol., 35: 515-528. DOI: 10.1016/0924-0136(92)90338-S

Baker, T.N., 2010. Laser Surface Modification of Ti Alloy. In: Surface Engineering of Light Alloys: Aluminium, Magnesium and Titanium Alloys, CRC Press, Oxford, UK., ISBN-10: 1845695372, pp: 398443.

Benyounis, K.Y., O.M. Fakron and J.H. Abboud, 2009. Rapid solidification of $\mathrm{M}_{2}$ high-speed steel by laser melting. Mater. Design, 30: 674-678. DOI: 10.1016/j.matdes.2008.05.030 
Bhadeshia, H.K.D.H., 2012. Steels for bearings. Progress Mater. Sci., 57: 268-435. DOI: 10.1016/j.pmatsci.2011.06.002

Costa, A.R.D., A. Craievich and R. Vilar, 2004. Phase transitions in $\mathrm{Nb}$ rich coating produced by laser alloying: A synchrotron radiation diffraction study. Mater. Sci. Eng. A, 336: 215-218. DOI: 10.1016/S0921-5093(01)01958-X

D’Oliveira, A.S.C.M., R.S.C. Paredes, F.P. Weber and R. Vilar, 2001. Microstructural changes due to laser surface melting of an AISI 304 stainless steel. Mater. Res., 4: 93-96. DOI: 10.1590/S151614392001000200009

Darmawan, W., J. Quesada and R. Marchal, 2007. Characteristics of laser melted AISI-T1 high speed steel and its wear resistance. Surface Eng., 23: 112119. DOI: $10.1179 / 174329407 X 169502$

Hoffmann, P. and R. Dierken, 2003. Temperature controlled hardening of single part tools for automotive industry with high power diode laser systems. Proceedings of the 2nd International WLTConference on Lasers in Manufacturing, (CLM' 03), Munich, pp: 1-5.

Kanapenas, R., 2001. Laser hardening of tool steels of various grades. Mater. Sci., 7: 10-14.
Liu, Y.F., J.S. Mua, X.Y. Xu and S.Z. Yang, 2007. Microstructure and dry-sliding wear properties of TiC-reinforced composite coating prepared by plasma-transferred arc weld-surfacing process. Mater. Sci. Eng. A, 458: 366-370. DOI: 10.1016/j.msea.2006.12.086

Luangpaiboon, P., 2011. Constrained response surface optimization for a laser beam welding process. J. Math. Stat., 7: 5-11. DOI: 10.3844/jmssp.2011.5.11

Majumdar, D., A.K. Nath and I. Manna, 2010. Studies on laser surface melting of tool steel-Part I: Surface characterization and it's electrochemical behavior. Surface Coat. Technol., 204: 1321-1325. DOI: 10.1016/j.surfcoat.2009.08.013

Sun, G., R. Zhou, P. Li, A. Feng and Y. Zhang, 2010. Laser surface alloying of C-B-W-Cr powders on nodular cast iron rolls. Surface Coat. Technol., 205: 2747-2754. DOI: 10.1016/j.surfcoat.2010.10.032

Yasavola, N., A. Abdollah-zadeha, M. Ganjalib and S.A. Alidokhta, 2013. Microstructure and mechanical behavior of pulsed laser surface melted AISI D2 cold work tool steel. Applied Surface Sci., 265: 653662. DOI: 10.1016/j.apsusc.2012.11.070 